\title{
Subperiosteal Gain and Endosteal Loss in Protein-Calorie Malnutrition
}

\author{
STANLEY M. GARN, MIGUEL A. GUZMÁN AND BETTY WAGNER \\ Center for Human Growth and Development, University of Michigan, \\ Institute of Nutrition of Central America and Panama, Guatemala City, \\ and Fels Research Institute, Yellow Springs, Ohio
}

\begin{abstract}
Subperiosteal and medullary cavity diameters of 91 Guatemalan boys hospitalized with a diagnosis of protein-calorie malnutrition show a slight but significant increase in total width but a marked reduction at the endosteal surface, and in cortical area and percent cortical area, indicative of continuing subperiosteal apposition and a dramatic excess of endosteal resorption.
\end{abstract}

In previous studies we were able to demonstrate tubular bone loss during the course of protein-calorie malnutrition in infants and children, as apart from simple failure to grow (Garn et al., '64a,b; Garn, Rohmann and Guzmann, '66; Garn, Rohmann and Silverman, '67). Our work closely confirmed the bone-mineral determinations of Fletcher and Garrow ('64) and indicated a magnitude of tissue bone loss as great as $40 \%$. We did not analyze the two bone surfaces, nor did we have access to the data from the Guatemalan Nutritional Survey. Recently, however, we have extended our analysis, using such national norms, and can document the surface-specific nature of bone loss in proteincalorie malnutrition in Central America.

Comparing radiogrammetric data on metacarpal widths of boys hospitalized with an admission diagnosis of Kwashiorkor, with our recent national survey data (Garn and Rohmann, '66) no systematic reduction in outer bone width is evident. Rather, subperiosteal diameters of the affected boys are slightly but significantly larger than expectancy, using a chi-squared test $\left(x^{2}=4.05, p=0.05\right)$. These data are shown in the first figure, and indicate that outer bone widths are not necessarily diminished, despite other growth failures.

However, there is a marked reduction of cortical bone at the endosteal surface, compared to the sex-specific Guatemalan norms. This is detailed in the second figure, and it is confirmed by the very high chi-squared value $\left(x^{2}=18.0\right)$ with a $p$ of less than 0.001 . Hence bone loss in ju- venile protein-calorie malnutrition is surface specific, and, as in adult bone loss, bone is lost at the endosteal surface and not at the subperiosteal. The subperiosteal surface may even continue to gain, in both juvenile and adult bone loss.

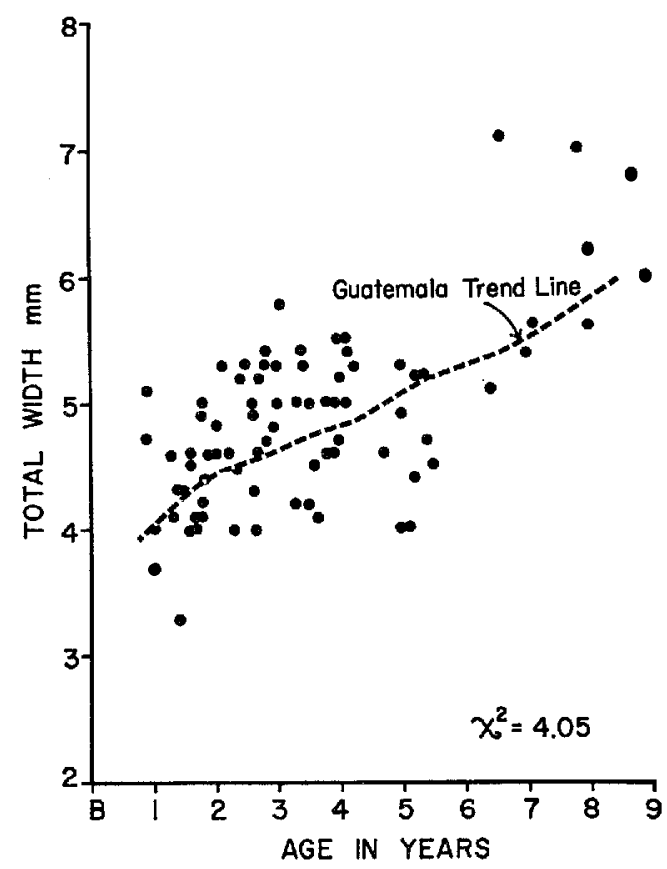

Fig. 1 Total width of the second metacarpal at midshaft in 91 Guatemalan boys with Kwashiorkor (solid dots) compared to normative values for 497 boys from the nation-wide survey. Despite extreme emaciation and marked debility at the time of admission the affected boys are slightly larger than the national norm (for total subperiosteal diameter). 


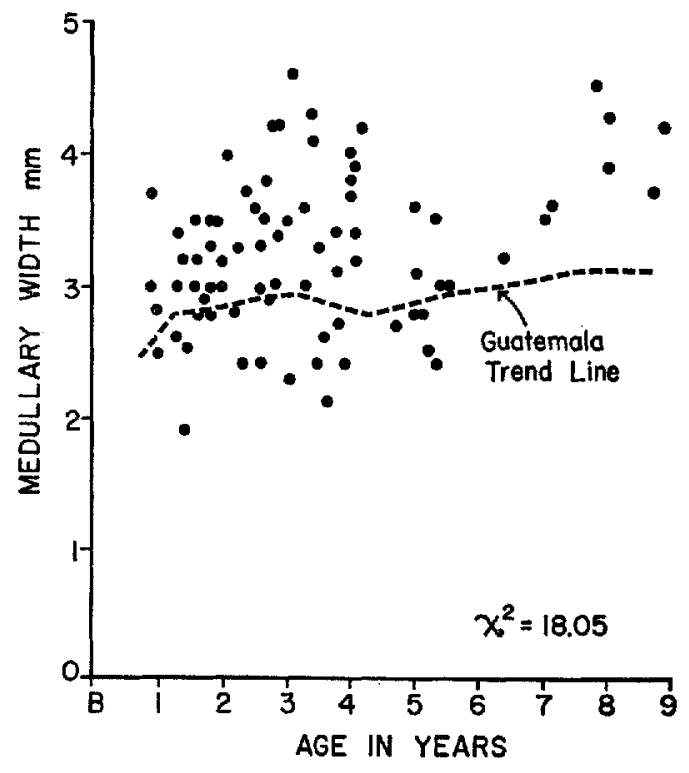

Fig. 2 Increased medullary width in proteincalorie malnutrition (solid dots) as compared with the Guatemalan national norm. In the affected boys, medullary width greatly exceeds the norm $\left(\chi^{2}=18.0\right)$, thus reducing the bony cortical wall to a thin shell.

With subperiosteal diameters slightly in excess of expectancy, but medullary cavity width greatly in excess of normal, the area of cortex in midshaft cross-section is also well below normal in the affected children. As shown in the third figure, there is approximately $30 \%$ less bone in the cross-section, despite the larger subperiosteal envelope. This reduction in cortical area is also highly significant, the value of $x^{2}$ being 14.5 , as depicted. Thus the slightly larger subperiosteal area is associated with a greatly diminished cortical area in the midshaft section.

With a greater midshaft diameter, but less bone in it, the percent of bone in the metacarpal cross-section is dramatically reduced in protein-calorie malnutrition, and this measure (percent cortical area) has maximum diagnostic value. Both the raw data and the value of chi-squared are given in the fourth figure, and show that the percent of bone in the cross-section has the greatest discriminatory effectiveness $\left(x^{2}=24.2\right)$.

These data analyses, taken together, confirm the remarkable ability of bone to maintain subperiosteal apposition at the expense of the endosteal surface. They further show the partial independence of the outer and inner bone surfaces. Though some medullary cavity expansion is "normal" in Guatemalan boys during the first decade of life, calculated endosteal loss rates in protein-calorie malnutrition prove to be at least three times normal.

Our earlier analyses of tubular bone loss, whether in infants or adults, were based upon cortical thickness (C), obtained by subtracting medullary width (M) from the total subperiosteal diameter (T). While T-M provided useful information, both in children and adults, it ignored the separate behaviors of the outer and inner bone surfaces, (cf. Garn, Rohmann, Wagner and Ascoli, '66, '67). Increasingly, separate attention to both the outer and inner bone surfaces provides information on the complex surface-specific behavior of bone.

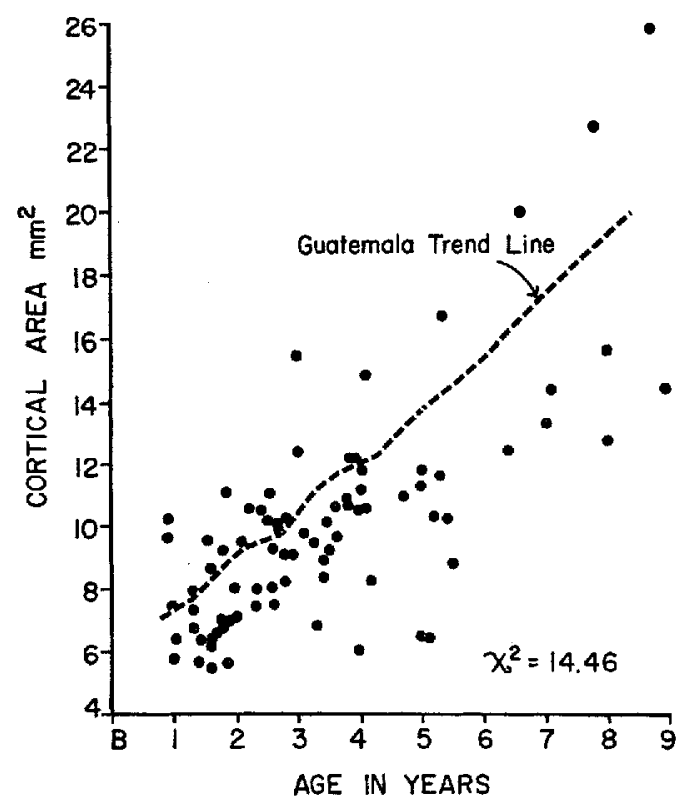

Fig. 3 Decreased cortical area in Kwashiorkor. Despite the slightly greater subperiosteal area, reduced cortical thickness leads to a greatly diminished cross-sectional area of the cortex with a consequent reduction in the breaking strength. Skull thickness is comparably reduced in affected children (cf. Garn, Rohmann and Guzman, '66) and osseous fragility is therefore a concomitant of advanced protein-calorie malnutrition. 


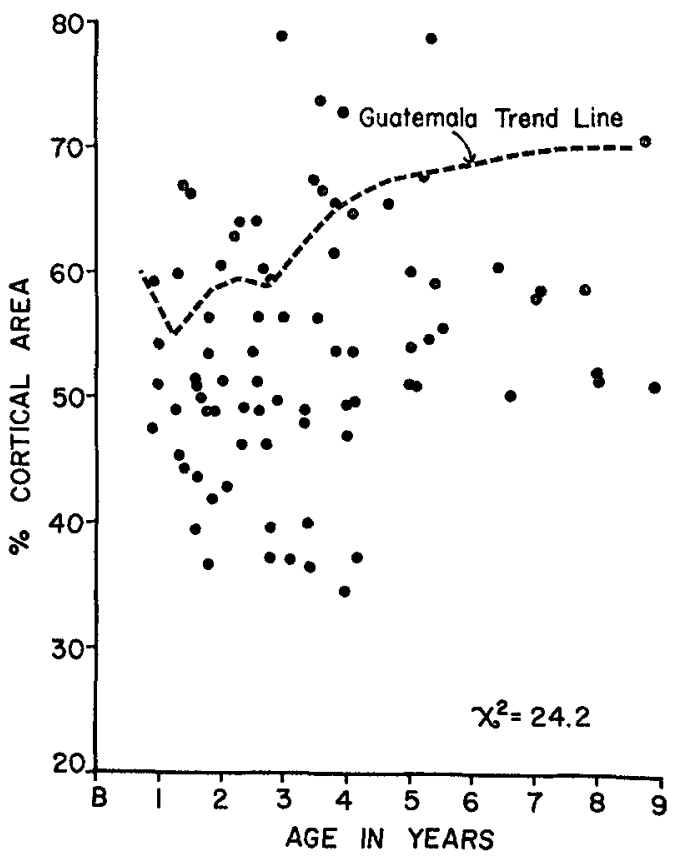

Fig. 4 Reduction in the percent of cortical area in the metacarpal midshaft. As with the tibia and other long bones, the amount of bone within the subperiosteal envelope is greatly reduced in protein-calorie maInutrition. This method of comparison is particularly applicable to population comparisons since differences in absolute bone size are effectively eliminated.

This can be shown in medullary stenosis, in the transient bone loss of infancy, in the adolescent shift to endosteal apposition, in endosteal apposition during pregnancy, in the concomitant outer-bone gain/inner-bone loss of later adulthood, and in the bone losses of malnutrition and malabsorption states.

\section{ACKNOWLEDGMENTS}

The work described in this report was made possible by a special international grant from the Nutrition Study Section and then completed under grants AM 08255 and AM 13378 from the National Institutes of Health.

\section{LITERATURE CITED}

Garn, S. M., M. Behar, C. G. Rohman, F, Viteri and D. Wilson 1964 Catch-up bone development in children with Kwashiorkor. Fed. Proc., 23: 338 .

Garn, S. M., and C. G. Rohman 1966 The gain and loss of cortical bone in Guatemala. Progress Report 66-2 on Contract PH 43-65-1006, Fels Research Institute, Yellow Springs, Ohio.

Garn, S. M., C. G. Rohmann, M. Behar, F. Viteri and M. A. Guzman 1964 Compact bone deficiency in protein-calorie malnutrition. Science, 145: 1444-1445.

Garn, S. M., C. G. Rohmann and M. A. Guzman 1966 Malnutrition and skeletal development in the pre-school child. Pre-School Child Malnutrition: Primary Deterrent to Human Prog. ress. National Academy of Sciences - National Research Council, pp. 43-62.

Garn, S. M., C. G. Rohmann and F. N. Silverman 1967 Radiographic standards for postnatal ossification and tooth calcification. Medical Radiography and Photo, 43; 45-46.

Garn, S. M., C. G. Rohmann, B. Wagner and W. Ascoli 1967 Continuing bone growth throughout life: A general phenomenon. Am. J. Phys. Anthrop., 26: 313-317.

- 1968 Further evidence for continuing bone expansion. Am. J. Phys. Anthrop., 28: 219-221.

Garrow, J. S., and K. Fletcher 1964 The total weight of mineral in the human infant. Brit. J. Nutr., 18: 409-412, 